\title{
Popularizing Natural Sciences by Means of Scientific Fair
}

\author{
http://dx.doi.org/10.3991/ijet.v6i4.1848 \\ Martin Cápay, Jozef Kapusta, Martin Magdin, Miroslava Mesárošová, Peter Švec, L’ubomíra Valovičová \\ Constantine the Philosopher University in Nitra, Nitra, Slovakia
}

\begin{abstract}
Science popularization is demanding from the financial as well as the time point of view. It is necessary to find the premises that would be easily available to general public. Another important step is to promote the event so that it would attract the audience. The preparation of scientific experiments itself also requires some financial resources. If we want to take advantage of these resources in the most useful and effective way, we have to find answers to the question: "What, where and how do we want to popularise?" In the paper, we describe one-day project aimed to popularization of scientific fields carried out by eight departments of the Faculty of Natural Sciences, Constantine the Philosopher University in Nitra. The project was named Scientific Fair - Science you can see, hear and experience. Its main goal was to present seven scientific fields - Physics, Informatics, Mathematics, Geography, Ecology, Chemistry and Biology. Popularization was carried out as experimental interactive activities unveiling the undisclosed corners of science. Their aim was to inspire the audience, arouse their interest in science and motivate the participants to cognitive activities. We introduce the idea of the project in detail concentrating mainly on informatics realized by the Department of Informatics.
\end{abstract}

Index Terms-popularization of science, workshop, gamesbased learning, educational games, algorithmization, multimedia.

\section{INTRODUCTION}

It is necessary to understand that scientific and technological literacy concerns anybody and everybody and is here for anybody and everybody [1]. The interest in natural sciences has been decreasing for the past few years. The roots of the lack of interest in life-long natural sciences or technology education lay in excessive formality in approach to education on lower levels, which does not spark off the interest of pupils.

In spite of growing popularity of fields of informatics, many people still have distorted ideas about what informatics as a science actually is. Informatics literacy is thereby often narrowed to a few routine operations. Many times, informatics is not used as an added value, and in many cases it even becomes a burden which can cause a wave of scepticism. But even informatics can be taught differently, by means of informal activities. It can be interconnected with other subjects, such as mathematics (algorithmization), physics and chemistry (simulations), or geography (geocaching).

The isolation of science and practice can be abolished by popularizing communication with the general public.

\section{POPULARIZATION OF SCIENCES}

What to imagine under this term? Popularization of science is nothing else than an endeavour to depict scientific ideas in such a way that everyone (especially nonscientists) can grasp the fundamental concepts and have an idea of what science in its essence is [2]. The primary role of popularization is then to transform scientific knowledge to a language understandable to an ordinary person [1].

The concept popularization evokes various methods and forms of presentation, typically some kind of workshop. It does not have to be an educational workshop; however, to fulfil the function of popularization it needs to be available to general public. Popularization is typically carried out as an experiment, a presentation, experiential activities or even an ordinary lecture. The aim of these activities, whatever their form is, has to be the effort to inspire the audience, arouse their interest in science and motivate the participants to cognitive activities. Of course, the most frequent target groups are children. Hence, the concept of activities must be simple and understandable. Stephen Hawking's "A Brief History of Time" is great example of an excellent populariser as he kept only one formula in this book [2] to make it understandable and interesting for the public.

\section{A. Popularizating science in the Slovak Republic}

The proposal of the Strategy of popularization of science and technology in society was approved by Slovak Government resolution no. 103 on February 7, 2007. However, even today the science popularization in general is not an easy task. In Slovakia, popularization is realised mainly via monothematic workshops as well as popularization lectures (Scientific Hour [3], Veda v Centre/Scientific Café - Science in Centre [4], Scientific patisserie [5]), mainly with the support of universities and organisations focusing on popularization (Slovak Centre of Scientific and Technical Information [6], Ministry of Education, Science, Research and Sport of the Slovak Republic [7], National Centre for Popularization of Science and Technology in Society [8], Slovak organization for research and development activities [9] Schola Ludus [10]). To overcome the barrier between the scientists and the rest of the public, so that the most general public can see the "human side" of the science and the scientists, is the aim of international project Researchers' night, in which Slovakia is taking part for the fifth time in 2011 [11]. In foreign countries, the form of scientific street stands is also used to present scientific "toys" popularizing science as such (Science and Technology in the Streets of Plzeň [12]). Scientific fair projects motivate the students 
PAPER

Popularizing NATURAL SCIENCES By MEANS OF SCIENTIFIC FAIR

to ask questions and to conduct personal research, they promote "discovery learning" provide accent on the scientific process, encourage ingenuity and initiative [13].

\section{SCIENTIFIC FAIR. SCIENCE AND FUN - ALL IN ONE}

In our case, we co-organized one-day project aimed to popularization of scientific fields carried out by eight departments of the Faculty of Natural Sciences, Constantine the Philosopher University in Nitra. The project was named Scientific Fair - Science you can see, hear and experience and was a part of exhibition called Interactive science. Its main goal was to present seven scientific fields - Physics, Informatics, Mathematics, Geography, Ecology, Chemistry and Biology. We wanted to popularize natural sciences so that pupils, students and general public would not find natural sciences artificial subjects to be learned at school, to "hate" and to not enjoy, but to see them as parts of ordinary life, which are to be found around us and to be counted on. The aim of scientific fairs is to "show that science can be seen, heard, but mostly experienced. On scientific fairs, the natural sciences are transformed from boring school subjects to things that surround us every day."

In the following text, we introduce the idea of the project in more detail; we deal with the marketing as well as the content point of view concentrating mainly on informatics realized by the Department of Informatics.

Scientific workshops are usually aimed at the narrow field of interest, most often they concentrate on physically-focused experiments. In our project this was not the case. We wanted to popularize not just one scientific field but seven different ones. This had in fact several advantages. Specifically it was the opportunity to offer the visitors a space where everyone picked out what he/she fancied. Every scientific field (stand of a particular department) concentrated on what they considered important and at the same time sought how to offer even the complex and difficult things in an interesting way.

\section{A. Suitable premises for scientific fair}

One possibility is to organize the fair where most fairs take place, namely in the streets in form of street stands. In this case, however, we may come across several "problems". It is not possible to build a street stand wherever and whenever, there are several rules and acts that have to be followed. Another problem of open public spaces may be the availability of electricity as well as the internet connection and, of course, there is always a possibility of bad weather. On the other hand, the greatest advantage, in our opinion, is the possibility to involve the city (with its representatives) in organizing the event and the fact that these premises are really public space.

Because of mentioned disadvantages we decided to find another premises to organise the Scientific Fair. Our experiences confirmed that from various points of view the best alternative is organising such event in a shopping centre. Nowadays, the shopping centres become centres of educational workshops (of course, with advertorial background) and other events, i.e. family ones. Both parts (the shopping centre and the organizer) may profit from the event. We managed to get the premises free of charge. The shopping centre, on the other hand, profited from the high visit rate since most of the visitors of the Scientific Fair headed to shop as well.

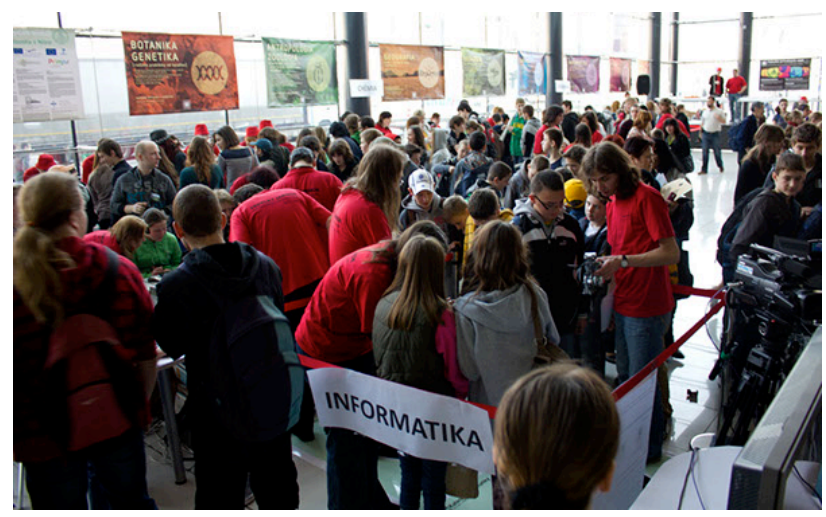

Figure 1. Scientific Fair - in the background there are the banners of particular departments [14]

\section{B. Marketing or how to attract the public}

Another part of the preparation is attracting the target group. We focused mainly at primary schools. We do not consider sending simple notice to particular schools the proper form of promotion. We believe that it is more valuable if we prepare information leaflet that would present the fair in a catching and at the same time "mysterious" way. It is not essential to write details. Children must feel that this is something special but will not find out the nature without personal involvement during the fair. In case of informatics we addressed the potential visitors as follows: How to use computers for playing and learning at the same time? Program your robot and greet your friends in the regional television broadcasting.

It is also important to inform wider public about the event as not everybody would get the leaflet. The role of advertising in regional newspapers as well as the large billboards in the fair premises at least one week before the event is essential. We chose the city-light form which is a type of outdoor advertising that is situated mainly in the streets, busy squares or bus stops. The banners were placed in the shopping centre near its main entrance where a lot of people could see them. This promotion was partially financed by the shopping centre and partially by the university. Each department was presented by own banner (Figure 1) that introduced it via slogan, aphorism or questions without answers. The Department of Informatics chose the slogans: "In informatics you are either number one or zero, there is no average." and "Bit or Byte? ... That is the question."

An important part of the event is the interest of mass media. In this case, regional as well as national televisions reported about the event. Several reports were published also in print media.

\section{What to present and when}

Many activities demonstrating basic science can be categorized as 'science is fun' [15], we fundamentally rejected stern presenting of scientific principles by means of projected beforehand conducted and recorded experiments. Our condition while choosing the topics was the ability to actively involve the audience. All of the activities were to be conducted based on the communication between the laic and the professional responsible for the experiment, i.e. on the activation methods principle. These methods are actually processes guiding the education in direction of making the educational aims reachable mostly 
PAPER

by means of one's own work. The choice of suitable topics for whole-day activity has to follow not only educational (popularization) but also organizational objectives. It is recommended to choose short experiments and enable as many interested visitors as possible to participate. Experiments (topics) should be changing cyclically. Since the visitors are scattered all over the place, the repetition of activities will make them believe they will not miss anything important. Consequently, their attention will arise. However, thematic change has to be realised quickly and unpretentiously. It is also advisable to insert podium appearance to attract and interest major part of the audience while the particular stands prepare another topic (experiments). In our case, the department of Physics with a long-time experience in the area took the job of podium appearances.

\section{SCIENTIFIC STAND OF THE DEPARTMENT OF INFORMATICS}

During the fair itself, our department concentrated on three basic areas: multimedia, robotics and informatics in practice. Of course, each block of activities got more catching name: How to train a robot, Learning by playing and Young editors.

\section{A. How to train a robot-Lego on the edge of a toy and educational tool}

An attractive tool for development of cross curricular connections between informatics and other subjects are robot kits. The pupils develop not only their ability to create algorithms for robot behaviour but also other key competences, i.e. team-working, reconsidering the solutions and critical evaluation [16].

Kits themselves encourage non-traditional organizing of the education and usage of educational methods leading pupils to

- understanding and designing of difficult action models, which often simulate real world appliances or events,

- capturing, processing and presenting data from the environment,

- solving of unfamiliar problems resulting from particular requirements on the function of the model in real world,

- active managing of their own work and setting their own targets,

- creativity and presentation of their own ideas and solutions [16].

During the past few years, several types of robotic kits for pupils and students appeared on the market, for example simple robotic toys for children such as BeeBot to more complicated kits such as Lego WeDo kit for primary school pupils. Five Lego Mindstorms NXT kits were available at the Scientific Fair (Figure 2). Lego Mindstorms NXT kit is a respectable "scientific toy", which allows demonstrating the principles of functioning of real robots. In addition to the basic NXT intelligent brick and the engines with the wheels it was also composed of two touch sensors, one sound sensor, one ultrasonic and one light sensor. Since the construction of the robot itself is quite time consuming, the ready-made robots were introduced at the fair in their basic form.

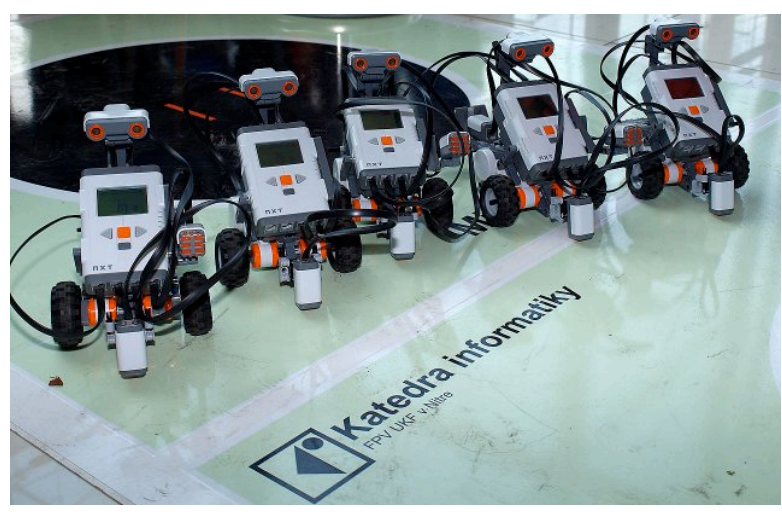

Figure 2. Robots - Lego Mindstorms NXT kits [17]

Specific needs of the Scientific Fair inspired us to have special pad constructed with two courses for the robots (black curve $1.5 \mathrm{~cm}$ wide) printed on it - it was made of a durable material that enables using the template on the table as well as on the floor. The courses on the pad are similar with the same lengths, start and finish. They were designed to test out how the robot follows the black line. As there were two similar courses, it was possible to compete two robots against one another in speed. In addition to the courses intended to follow the line, there was also a ring for MiniSumo competition printed.

For the visitors there were also the computers available to create simple programmes in iconographic programming environment Lego Mindstorms Education NXT. These could be transferred into the NXT bricks and the robot could be tested. For non-programmers and younger children we prepared several programs designed in advance, i.e. The Hitcher, remote-controlled robot. However, creation of programs directly on the NXT brick was more popular than programming via computer. To make the process of creation of new programs easier for the participants, there were command icons with short description printed on a leaflet that was available during the activity (Figure 3 ).

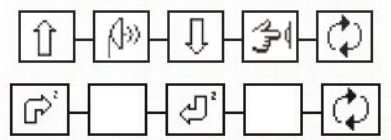

Figure 3. Programme "Moving forward and backward" and "Robot dances waltz"

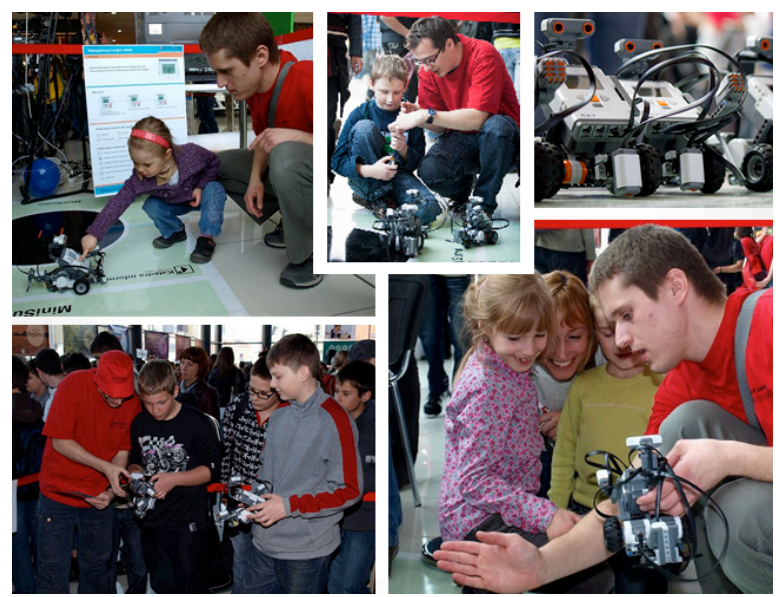

Figure 4. Activity How to train a robot [14] [117][18] 
PAPER

Popularizing NATURAL SCIENCES By MEANS OF SCIENTIFIC FAIR

The most interesting program among the young participants was the movement of the robot forward and backward while existence of an obstacle was the stimulus to change. Older visitors taught the robot to dance waltz (Figure 4).

According to available commands the participants were able to program e.g. a car that will not fall down of the table, a car that stops in front of an obstacle or beeps while driving rearward, etc. They were also shown how the robots react to the colour they are currently walking on. Our experiences show that the activities with sound sensor are not suitable for this type of workshop because of high level of noise in the premises of the fair.

The participants learnt what the algorithm, program or sensor is and they could test their knowledge by programming the robots. The activity dedicated to the robotics was one of the most interesting activities of the whole fair mainly thanks to the amount of practical demonstrations and the possibility to create and present own program. That was not a surprise since it exactly fulfilled the slogan of Scientific Fair about the science you can see, hear and experience.

\section{B. Learning by playing}

Games-based Learning (GBL) is about leveraging the power of computer games to captivate and engage endusers for a specific purpose, such as to develop new knowledge and skills. Games-based Learning enables learners to undertake tasks and experience situations which would otherwise be impossible and/or undesirable for cost, time, logistical and safety reasons. GBL has the potential to significantly improve training activities and initiatives.

If we compare a typical entertainment games technology based experience to a typical learning technology based experience the contrast is glaringly obvious. Games-based learning is not about using simplistic 'Pong' or 'Who wants to be a millionaire?' as a means to teach people raw facts. GBL is a subject of great amount of academic research. In the US, the Massachusetts Institute of Technology, Pennsylvania State University, Carnegie Mellon, the University of Southern California, Stanford University and the Naval MOVES Institute have undertaken significant research programmes. EA Games have funded NESTA in the UK to research the educational benefits of commercial off-the-shelf games. BECTA carried out a similar research project in 2001 entitled "Computer Games in Education Project". The University of Birmingham is also involved in a DTIfunded 'serious games' research project. [19]

According to Tway [20], multimedia also offers an excellent alternative to traditional teaching. By allowing the students to explore and learn at different paces, every student has the opportunity to learn at his/her full potential. Multimedia are intended to inform, nevertheless, they are also suggested for serious work, education as well as entertainment.

Within Scientific Fair in the field of multimedia and game-based learning promotion following activities were prepared:

1. Identikit - creation of graphical profile of a person

2. ZOO - virtual visit at the zoo
3. Morphing - animation effect, that changes (or morphs) one image into another through a seamless transition

4. On-line games

5. Magic applications - demonstration of number puzzles and mind reading

At the choice of multimedia software we aimed at those that are freely available so that the visitors could try them at home as well. Altogether, there were six notebooks prepared for the visitors and each activity was supervised by one of the teachers (Figure 6).

According to [21] "consistent with a generative theory of multimedia learning assumes that learners actively select relevant verbal and visual information, organize the information into coherent mental representations, and integrate these newly constructed visual and verbal representations with one another." Therefore in the first activity, called Identikit, the participants developed their observation skills as well as the ability to transform the observed reality into the new picture. It was very interesting to watch those who tried to portrait themselves - there was a webcam at each computer so that they could use real model.

The ZOO application was created by the students of the Department of Informatics within the subject Projecting of Multimedia Applications. The application is a kind of a simple encyclopaedia in which the student can find not only facts about chosen animals living in the $\mathrm{ZOO}$ but

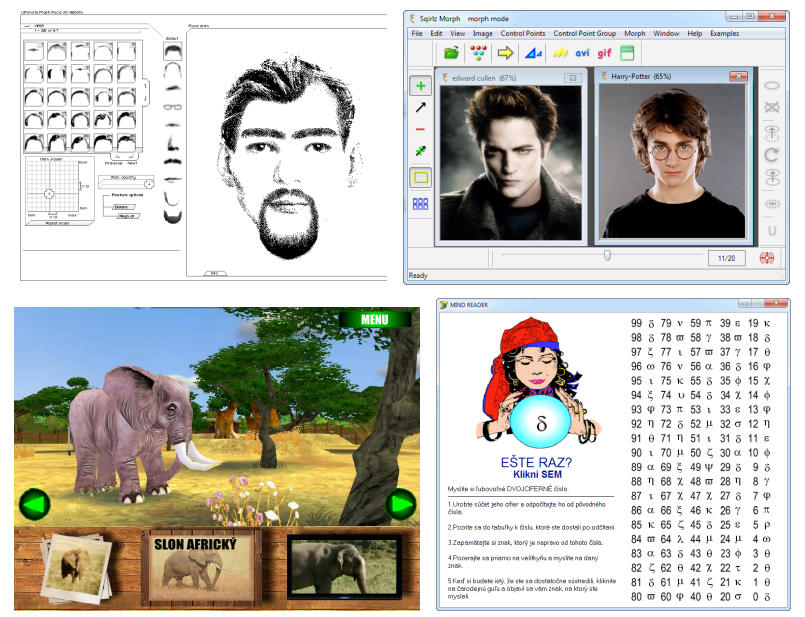

Figure 5. Demonstration of multimedia applications - Identikit, Sqirlz, ZOO and Mind Reader

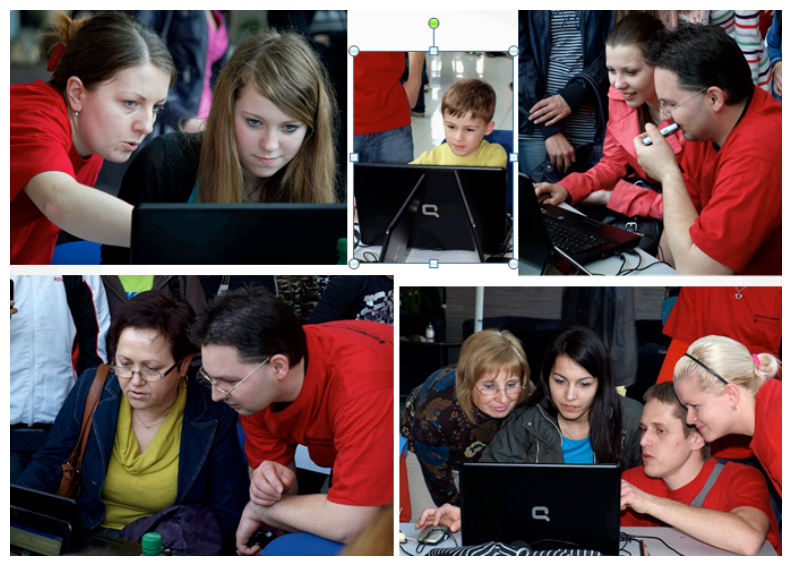

Figure 6. Activity Learning by playing [11][13] 
PAPER

Popularizing NATURAL SCIENCES By MEANS OF SCIENTIFIC FAIR

also a lot of pictures, videos and sounds of the animals. $\mathrm{ZOO}$ is accessible also to those who have not yet learned to read and write well, and provides context for learning. Therefore, it was intended mainly for the younger children.

In case of morphing, the aim is to change (morph) one picture into another. Participants could choose from the pictures prepared in advance and watch how the pixels of the first picture gradually change to project the second one. Webcam on the computers enabled them to take a photo of their own face and consequently use it as the initial or final phase of morphing - in this case they usually chose a picture of a famous person as the counterpart.

On-line games used within the event were chosen in order to present the terms algorithm and iconographic programming as well as to practice design of own algorithms to successfully pass particular levels of chosen games (IQ-marathon, LightBot). We were surprised how quite young children (5-7 years old) were able to create relatively complex algorithms while the older ones were able to pass only initial levels of particular game.

Other on-line activities were aimed at the visualisation of basic processes from the field of computer networks. CISCO have developed their Learning Game Trilogy, a combination of three online technology games: Rockin' Retailer, Network Defenders and SAN Rover. As part of the Cisco Career Certifications Program, these free games are offered as a challenge to individuals who are interested in learning while engaging in competitive game play [19]. One of the most fascinating trends in the adult learner market is the use of games to teach material required for job certification. Cisco has been a pioneer in pairing game-based learning with certification testing. Beginning with smaller scale offerings such as the Cisco binary game (teaches binary addition), the Cisco Learning Network now offers many mini-games and at least one game, Mind Share, that fully covers half the CCENT/CCNA curriculum required for Cisco certification [22].

At Scientific Fair we used Wireless Explorer (Spacecraft equipped with the latest Cisco wireless Technologies. Learner must welcome aboard an envoy of alien scientists sent to study the latest technologies on Earth and configure open wireless access to the ship's mainframe correctly for each alien), Binary Game (a fun way to learn binary numbers for networking) and Peter Packet (Peter must deliver a life saving message). Peter Packet is a part of Packetville, an online community packed with educational games, lesson plans, assessment materials, information for parents, awards for students, great graphics, catchy music, and loads of student activities that will help your students meet the national standards in educational technology. These were popular mainly among the boys. They understood the principles of home computer network. These games respect Bloom knowledge framework. A learner can gradually receive related knowledge via experiencing particular cognitive processes. Further, a learner can receive procedure knowledge (such as advantage comparison) via analyzing and evaluating all problem solving processes and may create a particular new knowledge to extend their domain knowledge [23].

Many parents may think that their children just play another games. However, there is a large difference between teachers' and parents' aspirations on the one hand and the reality on the other hand: "home computers typically ser- vice game playing - games that appear to have little connection with the agenda of the school" [24].

Concept of magic applications was based on the principle of a black box - they presented an interesting task which resembled the magic.

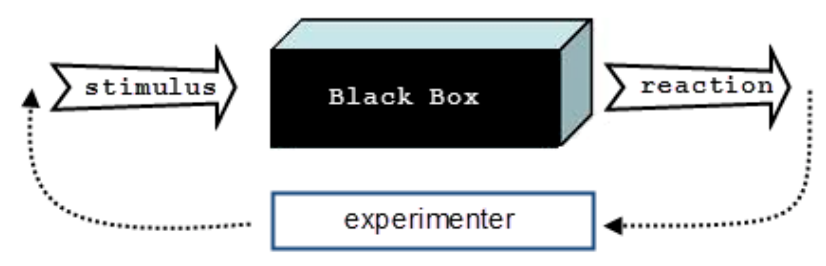

Figure 7. Scheme of the method of black box principle.

At the beginning of the experiment there are no assumptions of the black box operation. The student works with an application which is acting mysteriously, for example reading their mind. Of course, the student immediately thinks that the whole program works on basis of some kind of hidden principle (algorithm) they just do not know what it is yet, so the application is a kind of mystery to the user. Only a mechanism (instructions) is available, showing ways of interacting with the box (inputs). This way they can experiment with the application, explore its reactions (outputs) to different inputs, trying to solve this "mystery" (Figure 7). Students' aim is to observe the interaction between inputs and outputs and to make a protocol about their observations, which will be the basis for the formulation of the algorithm operating the box. [25]

Such activities can be used in teaching (decimal positioning system, transformation of binary to decimal code, etc.), or even in leisure activities in order to activate the students. Some tasks can be classified as cross-curricular themes of educational programs, in our case in particular topics in Mathematics. This type of activities was chosen by older visitors as well as the teachers from the secondary schools who express an interest in using them in their teaching. Applications working on the black box principle have been proved suitable also to brighten long university lectures.

All these activities were intended to help the participants understand what the algorithm, coding, identikit, morphing, router or binary code is.

\section{Young editors - Informatics in practice}

For those who wanted to see the informatics in practice we introduced the work of regional television TV Nitrička that was part of the stand of the Department of Informatics. At the same time, they were also a very important promotion partner - they introduced Scientific Fair in their broadcasting before, during and after the event. The participants could try standing in front of the video camera and conducting interviews.

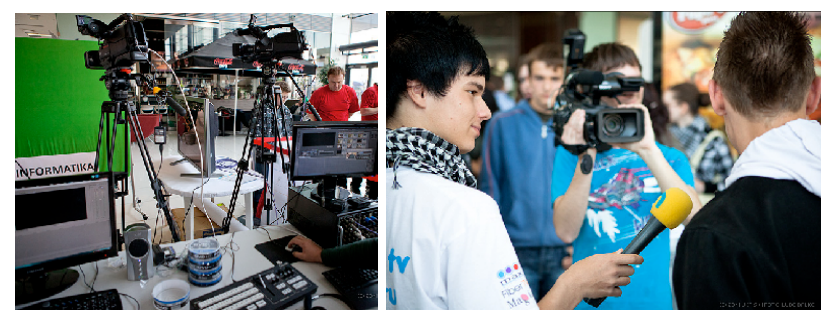

Figure 8. Activity Young Editors [18] 
They could experience working in front of the green screen and consequent keylighting. They could also watch the whole process of creation of a report e.g. for the news (Figure 8).

\section{CONCLUSION}

To find out the popularity of particular activities we used the method of a simple questionnaire in which we recorded the realised activity, its evaluation by the participants as well as the school (age) of the participants. These questionnaires were anonymous; they served only for the purpose of evaluation of particular activities within the Scientific Fair.

Visitor rate of the fair was unexpectedly high and the responses were only positive. For the visitors it was just a game - however, there was just a little step to real science. Very important for the success of the event was the attention of different media that created the image of the event via their own reports made independently from the organizers. Also from this side we met with positive feedback. To our surprise, several thank-you letters came and their positive response was aimed at the activities of our department. We may summarize that Scientific Fair was successful and our goals - to popularize the science and the departments as well - were fulfilled. Organizing informal activities can contribute to development of the general scientific and technological literacy of the public, which is very important for the development of the whole society.

\section{REFERENCES}

[1] Teplanová, K. Recommendations to the development of general scientific and technological literacy. SCHOLA LUDUS. 2000. Retrieved from www.scholaludus.sk/new/s1/Odporucania VTG.pdf

[2] G. C. Cornelis, Is Popularization of Science Possible? 1998. Retrieved from http://www.bu.edu/wcp/Papers/Scie/ScieCorn.htm.

[3] Slovac Academy of Sciences, Procect Scientific Hour. Retrieved from http://www.hodinavedy.sk/

[4] National Centre for Popularisation of Science and Technique in Society, Scientific Café - Science in Centr. Retrieved from https://www.vedatechnika.sk/SK/VEDAASPOLOCNOST/NCPV AT/Stranky/VEDAVCENTRE.aspx

[5] National Centre for Popularisation of Science and Technique in Society, Scientific patisserie. Retrieved from https://www.vedatechnika.sk/SK/VedaASpolocnost/NCPVaT/Stra nky/VedeckaCukraren.aspx

[6] Slovak Centre of Scientific and Technical Information,. Retrieved from http://www.cvtisr.sk/index/index.php

[7] Veda-Technika.sk, Informačný portál pre popularizáciu vedy, http://www.veda-technika.sk/index.html

[8] Národné centrom pre popularizáciu vedy a techniky v spoločnosti. Retrieved from https:/www.vedatechnika.sk/

[9] Slovak organization for research and development activities. Retrieved from http://www.sovva.sk/

[10] Schola Ludus. Centre for support of science education and nonformal lifelong science education at the Faculty of Mathematics, Physics and Informatics Comenius University in Bratislava, Slovakia. Retrieved from http://www.scholaludus.sk/

[11] Night of researchers - Researchers are among us. http://www.sovva.sk/noc-vyskumnika-2011/o-projekte0.html

[12] Interactive exhibition - Science and Technique in the Streets of Plzeň 2011. http://www.dnyvedy.zcu.cz/2011/projekt.php

[13] Why have a Science Fair? Retrieved from http://www.csun.edu/ $\lg 48405 /$ vsf $/ \operatorname{ch} 2 / \operatorname{ch} 2 . h t m l$

[14] Kadlečík M. Scientic Fair photogalery, Faculty of Natural sciences. Retrieved from http://www.fpv.ukf.sk/dokumenty/galeria/20110404_VedeckyJar mok/content/index.html
[15] Riise J. Communicating Science in Social Contexts 2008, 3, 301309, DOI: 10.1007/978-1-4020-8598-7_18, Bringing Science to the Public. http://dx.doi.org/10.1007/978-1-4020-8598-7_18

[16] Tomcsányi, P. et. al: Robotické stavebnice vo vzdelávaní - Ďalšie vzdelávanie učitel’ov základných škôl a stredných škôl v predmete informatika. ŠPU Bratislava, 2010.

[17] Tóth, T. Scientic Fair photogalery, Department of Informatics. Retrieved from www.ki.fpv.ukf.sk/sk/fotogaleria/category/29vedecky-jarmok-2011

[18] Balko, L. Scientic Fair photogalery, Constantine the Philosopher University in Nitra. Retrieved from http://www.ukf.sk/dokumenty/fotogaleria/jarmok2011/

[19] Corti, K.. Games-based Learning; a serious business application, 2006. Retrieved from

http://www.pixelearning.com/docs/games_basedlearning_pixelear ning.pdf

[20] Tway, L., Multimedia in Action. MA: AP Professional, 1995.

[21] Plass, J.L., Chun, D.M., Mayer, R.E. and Leutner, D. Supporting visual and verbal learning preferences in a second language multimedia learning environment. Journal of Educational Psychology, 90(1), 1998, 25-36. http://dx.doi.org/10.1037/0022-0663.90.1.25

[22] McQuerry, S. Cisco CCENT Mind Share Game and Interconnecting Cisco Network Devices, Part 1 (ICND1) Bundle: Cisco Press. 2010.

[23] Wang, C. S., \& Li, Y. C. Integrated network management certification training with computer game: A knowledge placement framework, Seoul. 2009

[24] Bourgonjon, J., Valcke, M., Soetaert, R., de Wever, B., \& Schellens, T. Parental acceptance of digital game-based learning. Computers \& Education, 57(1), 2011 1434-1444. doi: 10.1016/j.compedu.2010.12.012. http://dx.doi.org/10.1016/j.comp edu.2010.12.012

[25] Cápay, M. \& Magdin, M. Puzzles, codes and ciphers for supporting of Algorithmic Thinking. In: Alternativní metody. Praha. 2011.

[26] Scientific Fair, activity Learning by playing. Retrieved from http://www.ki.fpv.ukf.sk/sk/ucme-sa-hrou

\section{AUTHORS}

M. Cápay is an assistant professor at Department of Informatics, Faculty of Natural Sciences, Constantine the Philosopher University in Nitra, Tr. A. Hlinku 1, 94974 Nitra, Slovakia. (email: mcapay@ukf.sk)

J. Kapusta is an assistant professor at Department of Informatics, Faculty of Natural Sciences, Constantine the Philosopher University in Nitra, Tr. A. Hlinku 1, 94974 Nitra, Slovakia. (email: jkapusta@ukf.sk)

M. Magdin is a researcher at Department of Informatics, Faculty of Natural Sciences, Constantine the Philosopher University in Nitra, Tr. A. Hlinku 1, 94974 Nitra, Slovakia. (email: mmagdin@ukf.sk)

M. Mesárošová is a researcher at Department of Informatics, Faculty of Natural Sciences, Constantine the Philosopher University in Nitra, Tr. A. Hlinku 1, 94974 Nitra, Slovakia. (email: mmesarosova@ukf.sk)

P. Švec is an assistant professor at Department of Informatics, Faculty of Natural Sciences, Constantine the Philosopher University in Nitra, Tr. A. Hlinku 1, 94974 Nitra, Slovakia. (email: psvec@ukf.sk)

L. Valovičová is an assistant professor at Department of Physics, Faculty of Natural Sciences, Constantine the Philosopher University in Nitra, Tr. A. Hlinku 1, 94974 Nitra, Slovakia. (email: 1valovicova@ukf.sk)

This article is an extended version of a paper presented at the International Conference ICL 2011, held in September 2011 in Piešt'any, Slovakia. Submitted, October 30th, 2011. Received 16 October 2011. Published as resubmitted by the authors 22 November 2011 . 